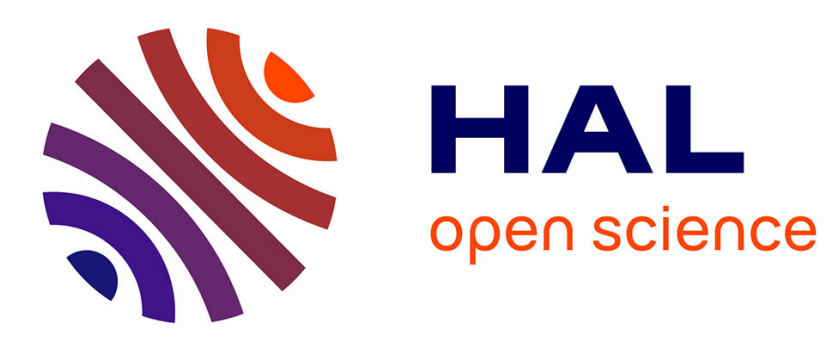

\title{
Probing wettability alteration of boron nitride surface through rheometry
}

\author{
Adrian Korycki, France Chabert, Valérie Nassiet
}

\section{To cite this version:}

Adrian Korycki, France Chabert, Valérie Nassiet. Probing wettability alteration of boron nitride surface through rheometry. Langmuir, 2019, 35 (1), pp.128-140. 10.1021/acs.langmuir.8b03025 . hal-02139301

\section{HAL Id: hal-02139301 https://hal.science/hal-02139301}

Submitted on 24 May 2019

HAL is a multi-disciplinary open access archive for the deposit and dissemination of scientific research documents, whether they are published or not. The documents may come from teaching and research institutions in France or abroad, or from public or private research centers.
L'archive ouverte pluridisciplinaire HAL, est destinée au dépôt et à la diffusion de documents scientifiques de niveau recherche, publiés ou non, émanant des établissements d'enseignement et de recherche français ou étrangers, des laboratoires publics ou privés. 


\section{OATAO \\ Open Archive Toulouse Archive Ouverte}

\section{Open Archive Toulouse Archive Ouverte (OATAO)}

OATAO is an open access repository that collects the work of Toulouse researchers and makes it freely available over the web where possible

This is an author's version published in: http://oatao.univ-toulouse.fr/21726

Official URL: https://dx.doi.org/10.1021/acs.langmuir.8b03025

To cite this version:

Korycki, Adrian $\rightleftharpoons$ and Chabert, France $\leftrightarrows$ and Nassiet, Valérie $=$ Probing wettability alteration of boron nitride surface through rheometry. (2019) Langmuir, 35 (1). 128-140. ISSN 0743-7463

Any correspondence concerning this service should be sent to the repository administrator: tech-oatao@listes-diff.inp-toulouse.fr 


\title{
Probing Wettability Alteration of the Boron Nitride Surface through Rheometry
}

\author{
Adrian Korycki, France Chabert, ${ }^{*}$ Tiphaine Mérian, and Valérie Nassiet \\ LGP ENIT INPT, Université de Toulouse, 47 Avenue d'Azereix, BP1629 65016 Tarbes Cedex, France
}

\begin{abstract}
While the surface of many ceramic particles is covered by positive and negative species, boron nitride displays no charge on the surface. Nevertheless, the interest in boron nitride is rising: Little materials combine electrical insulation and high thermal conductivity; both properties are required for many applications, for instance, in electronic devices and sensors. Hydroxyl $(-\mathrm{OH})$ groups are usually created on the surface to increase the hydrophilicity of particles. In this work, we compare four treatments to select the one that increases most significantly the hydrophilicity of hexagonal boron nitride platelets, that is to say, for which the most $-\mathrm{OH}$ groups are grafted onto the surface. The treated particles have been studied by SEM, FTIR, and XPS. Our results show that these techniques are not appropriate to probe slight chemical changes. Indeed, hydroxyl groups are more likely introduced on the edges of the platelets. The highest hydroxyl concentration corresponds to $2.4 \%$ of boron

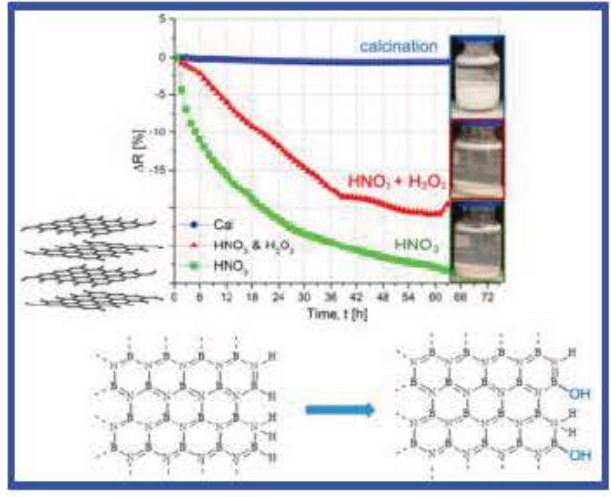
atoms functionalized. The settling of low concentrated suspensions has been followed by optical visualization. Multiple light scattering was used for high concentrated suspensions. The rheological behavior of stable suspensions in water and isopropanol has been determined by transient flow and dynamic tests. Measuring the viscosity of suspensions appears as a way to evaluate the surface alterations of boron nitride. The method involving thermal treatment is the most efficient to increase the concentration of hydroxyl groups when the particles are suspended in water. The treatment with nitric acid seems to be the most efficient when the particles are suspended in isopropanol. Moreover, the thermal treatment is more environmentally friendly than using strong acids or bases. Hydroxylated particles can be used either as a starting material for further modification such as covalent functionalization or directly to prepare suspensions or polymeric based composites.
\end{abstract}

\section{INTRODUCTION}

Tailoring surface interactions of particles is the key parameter to control wetting, adhesion, or stability of suspensions. Indeed, the properties of hybrid polymer-ceramic composites are driven by a strong ceramic-polymeric matrix adhesion at the interfaces, resulting in improved mechanical and thermal properties. In the latter case, the strong adhesion insures a continuous transfer of mass and wave propagation, the main phenomena responsible for heat transfer. Similarly, the tight cohesion at the interfaces permits a homogeneous repartition of mechanical stresses when the composite materials are subjected to strain. Additionally, multiple forming processes of ceramic materials are based on colloidal suspensions. ${ }^{1}$ These processes require a step of dispersing particles in a solvent: slip and tape casting, ${ }^{2-5}$ hot pressing, ${ }^{6}$ injection molding, and more. Again, the stability of suspensions permits a homoge neous repartition of particle sizes and, thus, isotropic properties in the final ceramic or composite parts.

Among affordable thermally conducting ceramics, boron nitride (BN) presents the highest thermal conductivity $(\sim 400$ $\left.\mathrm{W} \cdot \mathrm{m}^{-1} \cdot \mathrm{K}^{-1}\right)$ compared to alumina $\left(\mathrm{Al}_{2} \mathrm{O}_{3}, \sim 30 \mathrm{~W} \cdot \mathrm{m}^{-1} \cdot \mathrm{K}^{-1}\right)$, fused silica $\left(\mathrm{SiO}_{2}, \sim 1.5 \mathrm{~W} \cdot \mathrm{m}^{-1} \cdot \mathrm{K}^{-1}\right)$, aluminum nitride (AlN, $\left.\sim 300 \mathrm{~W} \cdot \mathrm{m}^{-1} \cdot \mathrm{K}^{-1}\right)$, silicon nitride $\left(\mathrm{Si}_{3} \mathrm{~N}_{4}, \sim 80 \mathrm{~W} \cdot \mathrm{m}^{-1} \cdot \mathrm{K}^{-1}\right)$, and silicon carbide $\left(\mathrm{SiC}, \sim 110 \mathrm{~W} \cdot \mathrm{m}^{-1} \cdot \mathrm{K}^{-1}\right)$. Hexagonal boron nitride ( $\mathrm{h} \mathrm{BN}$ ), the most stable of the $\mathrm{BN}$ crystalline structures, i.e., cubic, rhombohedral, presents numerous advantages such as a relatively low dielectric constant (around 4), resistance to oxidation, high thermal stability, low density, and excellent lubricating properties.

Hexagonal boron nitride ( $\mathrm{h} \mathrm{BN}$ ) can be encountered under different forms: $\mathrm{BN}$ platelets, $\mathrm{BN}$ nanosheets (BNNSs), and $\mathrm{BN}$ nanotubes (BNNTs) that are the structural isoelectric analogues of graphite, graphene, and carbon nanotubes (CNTs), respectively. Hexagonal boron nitride presents a layered structure, in which BNNSs, corresponding to a hexagonal network consisting of alternation of boron and nitrogen atoms covalently bonded, are stacked together thanks to van der Waals interactions in such a way that in neighboring sheets atoms follow this sequence BNBNB... on top of each other. The layered structure of $\mathrm{h} \mathrm{BN}$ platelets causes the anisotropy of the thermal conductivity that is much higher within the planes (up to $600 \mathrm{~W} \cdot \mathrm{m}^{-1} \cdot \mathrm{K}^{-1}$ ) than perpendicular 
to them $\left(\sim 30 \mathrm{~W} \cdot \mathrm{m}^{-1} \cdot \mathrm{K}^{-1}\right)$. In the crystal structure of hexagonal $\mathrm{BN}$ platelets and BNNSs, the edge plane differs greatly from the basal plane. The basal planes present a smooth surface with no functional groups, whereas some hydroxyl and amino groups are on the edges. The limited number of functional groups on $\mathrm{h} \mathrm{BN}$ surfaces explains its poor solubility and wettability: it is why $\mathrm{h} \mathrm{BN}$ is qualified as a chemically inert material. For this reason, preparing stable boron nitride suspensions or homogeneously dispersed boron nitride particles in composites is challenging. In order to avoid boron nitride particle aggregation and to permit their homogeneous dispersion either in composite matrixes or suspensions, surface modification is employed, either by covalent $^{7-21}$ or noncovalent ${ }^{22-36}$ functionalization.

Covalent functionalization involves the presence of chemi cally active functional groups on the $\mathrm{h} B N$ surface such as amino or hydroxyl groups, which can further react with a foreign molecule bearing the adequate chemical func tion. $^{9-13,16-19}$ For example, Zhi et al. ${ }^{12}$ have used an esterification reaction between hydroxylated BNNTs (BNNTs-OH) and carboxylic acids, perfluorobutyric acid, and thioglycolic acid, to covalently attach perfluoroalkyl chains or thiol groups, respectively, on the BNNT surface. Silane treatments $^{8,13,16,18,19}$ have also been employed on $\mathrm{h} \mathrm{BN}$ particles comprising hydroxyl groups on their surface. One end of the silane molecule, trimethoxy or triethoxy group, covalently bound on the $\mathrm{h}$ BN surface, while the other end presents a chemical affinity with the polymer matrix or the solvent used, allowing a better dispersion in the organic or aqueous phase. In the same manner, amino groups on the BNNT surface were further modified using isocyanate groups, ${ }^{17}$ acyl chlorides, ${ }^{9,10}$ or carboxylic acid groups. ${ }^{11}$

However, the low amount of chemically active functional groups naturally present on the $\mathrm{h} B N$ surface due to the high stability of BN bonds limits the effectiveness of any surface reaction. Several treatments ${ }^{7,8,10-12,14-16,18-21,37}$ have been experimented to increase the density of such functional groups and thus to activate the surface for further efficient modifications. Hydroxyl groups on the BNNT surface have been introduced by oxidizing BNNTs in hydrogen peroxide $\left(\mathrm{H}_{2} \mathrm{O}_{2}\right)$ at $120{ }^{\circ} \mathrm{C}$ under pressure. ${ }^{12}$ Hydroxyl groups were also covalently attached to the surface of $\mathrm{h} \mathrm{BN}$ particles using sodium hydroxide $(\mathrm{NaOH})$ treatments. $^{18-20}$ Lee et al. ${ }^{20}$ obtained hydroxyl functionalized $\mathrm{h} \mathrm{BN}$ nanoplatelets soluble in various solvents, e.g., water, isopropyl alcohol by ball milling of $\mathrm{h} \mathrm{BN}$ powders in the presence of sodium hydroxide solution. Chemical surface modification with nitric acid $\left(\mathrm{HNO}_{3}\right)^{16}$ is also another way used to introduce hydroxyl groups on the BNNT surface. Plasma treatments using oxygen, ${ }^{15}$ hydrogen, ${ }^{7}$ ammonia, ${ }^{10,11}$ urea, ${ }^{37}$ or a mixture of nitrogen and hydrogen ${ }^{15}$ gas have been applied on $\mathrm{h} \mathrm{BN}$ particles in order to chemically modify their surface. Ikuno et al. ${ }^{10,11}$ have covalently functionalized BNNT surfaces with amine functional groups using an ammonia plasma; the obtained BNNTs $-\mathrm{NH}_{2}$ present a good solubility in chloro form. Recently, Lei reports urea assisted ball milling, leading to exfoliation and $\mathrm{NH}_{2}$ functionalization. ${ }^{37}$ Covalent functional ization can alter the intrinsic electronic properties of BNNTs; for example, Zhi et al. ${ }^{9}$ have observed $\mathrm{p}$ and $\mathrm{n}$ doping of BNNTs but no electrical conductivity change has ever been reported to date. The chemical functionalization of $h \mathrm{BN}$ particles allowing a better solubility and dispersion in a polymer or an aqueous/organic solution without the introduction of a foreign material is of great interest. Nevertheless, it looks that the effectiveness of all of these treatments has never been compared until now.

Another method to improve the dispersion of $\mathrm{h} \mathrm{BN}$ particles in aqueous and organic solutions consists of noncovalent functionalization of the $\mathrm{h} \mathrm{BN}$ surface by surfactants or polymers. Noncovalent functionalization of the $\mathrm{h} B N$ sur face $20,22-36$ implies weak interactions such as $\pi-\pi$ stack ing $23,25,26,29,33,36$ with a foreign molecule. The h BN surface presents $\pi$ electronic structure implied by its chemical structure. Zhi et al. ${ }^{23}$ have used a conjugated polymer, poly $[m$ phenylenevinylene co (2,5 dioctoxy p phenyleneviny lene)] (PmPV), to wrap BNNTs. The PmPV functionalized BNNTs are soluble in chloroform and tetrahydrofuran, for example, but not in water or alcohol. Later, this strategy was employed to develop a BNNT purification method from larger h BN particles. $^{25}$ Other molecules comprising a conjugated structure such as a pyrene derivative (pyrene carboxylic acid ${ }^{36}$ ) and a perylene derivative (perylene 3,4,9,10 tetracarboxylic acid tetrapotassium salt ${ }^{26}$ ) have also been used to functionalize BNNTs; their good solubility and dispersion in ethanol and water, respectively, were observed. In another way, molecules with an amine functional group such as oleylamine, ${ }^{20}$ octadecylamine, ${ }^{31,35}$ and amine terminated polyethylene gly $\mathrm{col}^{22,28}$ have been used to interact with the $\mathrm{h}$ BN structure and noncovalently modify their surface in order to improve their affinity with their host phase.

Tailoring the surface chemistry of boron nitride is still in its early stages, and effective surface functionalization remains a challenging task. Despite many methods, none of them appears to be the most effective, as no study has attempted to compare their effectiveness. This work hereby intends to complete this task. We aim to compare four treatments to select the most efficient on increasing the wettability by creating $(-\mathrm{OH})$ groups on boron nitride platelets.

After modifying the surface of inorganic particles, the efficiency of the treatment is usually proved by comparing raw/ modified particles with various techniques of characterization. XPS (X ray photoelectron spectroscopy) is the only technique that gives a quantitative analysis of the chemical elements located at the extreme surface (depth of a few nanometers). However, probing slight chemical changes is difficult with XPS analysis, yet more when the signals of several chemical bonds are superimposed in one peak. In this case, it is necessary to deconvolute the peaks in a sum of several hidden peaks, making the result highly subjective. Other techniques require one to suspend the particles in a liquid medium and to characterize the so obtained suspensions. The easiest and cheapest method consists of observing the kinetics of settling of particles, either by taking pictures of suspensions or by measuring their transmittance in the UV-visible wavelength range. When the surface of hydrophobic particles is in contact with a polar solvent, the particles drop down rapidly. After surface modification, the stability of suspensions is longer because of interparticle forces. However, this method only gives a qualitative appreciation.

The zeta $(\zeta)$ potential is another indirect piece of evidence of the efficiency of treatments. The $\zeta$ potential is based on the measurement of electrophoretic mobility. The dissociation of the dispersion liquid generates ions; the latter come to the particle surface to form a layer of ions, called the electrical double layer (EDL). Stern has first developed this model as far as 1924. This EDL is composed of a first layer (Helmholtz 
layer) made of absorbed ions of charge opposite to the surface particle charge. The second layer (the Gouy-Chapman layer) or the diffuse layer is formed by ions attracted to the first layer charge via Coulomb forces that screen the first layer. Upon an electric field applied across the suspension, other ions dissociated in the liquid will move toward the electrode of opposite charge with a velocity proportional to the $\zeta$ potential. A high $\zeta$ potential indicates strong electrostatic repulsions between particles that confer stability to suspensions. Never theless, low concentrations are needed to get a reliable measurement of ion mobility and the $\zeta$ potential drastically changes with concentration; it is why only a few authors have used it to characterize particle mobility in high concentrated suspensions.

Lastly, rheometry is a probing technique to demonstrate the efficiency of surface modification of particles. For a reliable result, homogeneous and stable suspensions are needed. Viscosity of suspensions is an indicator of the intensity of repulsion between charged particles: the highest is the viscosity, the strongest the repulsion between particles, the longest will be the stability of suspensions. ${ }^{38}$ Capillary rheometers as well as oscillatory rheometers in permanent shear and oscillatory shear mode are used to characterize the flowing behavior of ceramic suspensions. ${ }^{1}$

The work presented hereby aims to compare the effectiveness of chemical treatments applied to boron nitride particles to increase the concentration of hydroxyl $(-\mathrm{OH})$ groups onto the surface. Four different treatments have been applied to boron nitride particles. Low concentrated and high concentrated suspensions have been prepared with treated particles in water and isopropanol. From simple viscosity measurements of suspensions, we probe the alteration of surface chemistry, correlated with the settling of suspensions with time.

\section{EXPERIMENTAL PROCEDURE}

Materials. Boron nitride (h BN) particles (CarboTherm Platelets $\mathrm{CTP}_{2}$ ) with an average size of $2 \mu \mathrm{m}$, a maximum particle size of 10 $\mu \mathrm{m}$, and a surface area of $10 \mathrm{~m}^{2} \cdot \mathrm{g}^{-1}$ were purchased from Saint Gobain Boron Nitride products (Saint Gobain Ceramic Materials, Amherst, NY). The composition is pure hexagonal boron nitride possibly containing $0.1-8 \%$ of boron oxide. Sodium hydroxide $(\mathrm{NaOH})$ in pellets and nitric acid solution $\left(\mathrm{HNO}_{3}, 65 \% \mathrm{w} / \mathrm{w}\right)$ were supplied by BDH Prolabo. Hydrogen peroxide solution $\left(\mathrm{H}_{2} \mathrm{O}_{2}, 35 \%\right.$ $\mathrm{w} / \mathrm{w})$ for analysis was provided by Acros Organics. Ethanol and isopropanol (absolute) were obtained from Fisher Scientific. All chemicals were used as received without purification.

Chemical Treatments. Prior to any further treatment, the pristine h BN particles were calcinated in a furnace at $625^{\circ} \mathrm{C}$ for $20 \mathrm{~min}$ in order to remove any organic contamination. Calcinated $\mathrm{h}$ $\mathrm{BN}$ particles are considered as a reference to study further treatments and are identified as "calcinated". h BN particles were subjected to the following chemical treatments in order to introduce hydroxyl $(-\mathrm{OH})$ groups on their surface.

Treatment with a basic solution: h BN particles were dispersed in 5 $\mathrm{M} \mathrm{NaOH}$ solution under reflux at $120{ }^{\circ} \mathrm{C}$ for $24 \mathrm{~h}^{18}$

Treatment with an acidic solution: $\mathrm{h}$ BN particles were dispersed in $\mathrm{HNO}_{3}$ solution $(65 \% \mathrm{w} / \mathrm{w})$ and sonicated for $6 \mathrm{~h}^{16}$

Treatment with an oxidizing solution: $\mathrm{HNO}_{3}$ treated $\mathrm{h} \mathrm{BN}$ particles were sonicated in $\mathrm{H}_{2} \mathrm{O}_{2}(35 \% \mathrm{w} / \mathrm{w})$ solution for $1 \mathrm{~h}$.

After each chemical treatment, the hydroxylated $\mathrm{h}$ BN (referred as $\mathrm{h} \mathrm{BN}-\mathrm{OH}$ ) particles were rinsed with deionized water and filtered several times until a neutral $\mathrm{pH}$ was obtained. The treated particles were dried in an oven at $110^{\circ} \mathrm{C}$ for $4 \mathrm{~h}$, cooled to room temperature, and then stored in a desiccator until preparation of suspensions.
Preparation of Suspensions. Raw, calcinated, and treated h BN particles were suspended in water (dynamic viscosity: $0.913 \mathrm{mPa} \cdot \mathrm{s}$ at $25{ }^{\circ} \mathrm{C}$ ) and isopropanol (dynamic viscosity: $2.055 \mathrm{mPa} \cdot \mathrm{s}$ at $25^{\circ} \mathrm{C}$ ). The concentrations range from $\phi=2 \mathrm{vol} \%$ to $\phi=18 \mathrm{vol} \%$ corresponding to 41 to $369 \mathrm{mg} \cdot \mathrm{mL}^{-1}$. The density is $1.000 \mathrm{~g} \cdot \mathrm{mL}^{-1}$ for water, $0.786 \mathrm{~g} \cdot \mathrm{mL}^{-1}$ for isopropanol, and 2.267 for $\mathrm{h} \mathrm{BN}$ particles. The so obtained suspensions were sonicated for $10 \mathrm{~min}$ and stirred by an agitator vibrating for $5 \mathrm{~min}$ at room temperature. The suspensions were kept at room temperature in tightly closed bottles to prevent solvent evaporation.

Characterization of Particles and Suspensions. Scanning electron microscope observation (EVO HD 15 LS by ZEISS) was used to measure the size of boron nitride particles at a pressure of the chamber of $40 \mathrm{~Pa}$. Infrared spectra were recorded using a Fourier transform spectrometer (Spectrum One by PerkinElmer) in attenuated total reflectance (ATR) mode in the $4000-650 \mathrm{~cm}^{-1}$ range. The resolution was $4 \mathrm{~cm}^{-1}$, and 16 scans were accumulated for an improved signal to noise ratio.

$\mathrm{X}$ ray photoelectron spectroscopy (K Alpha by Thermo Scientific) was carried out using an $\mathrm{Al} \mathrm{K} \alpha$ monochromatic $\mathrm{X}$ ray source at 1486.6 $\mathrm{eV}$. The curve fitting was performed using Avantage software (Thermo Scientific).

The kinetics of settling was studied at room temperature $\left(21^{\circ} \mathrm{C}\right)$ using the multiple light scattering analyzer Turbiscan Lab from Formulaction, Toulouse, France, equipped with a robotized autosampler (by CTC Analytics). The sample was introduced in a $20 \mathrm{~mL}$ glass cylindrical cell and scanned using a light beam emitted in near infrared ( $850 \mathrm{~nm}$ wavelength). The scans were recorded every 60 min up to 10 days; each scan lasts $17 \mathrm{~s}$. Transmitted and backscattered photons are analyzed using detectors placed, respectively, at 0 and $135^{\circ}$ from the incident beam direction.

The rheological properties of $\mathrm{h} B N$ suspensions were measured with a MCR 302 rheometer from Anton Paar at $23{ }^{\circ} \mathrm{C}$ in oscillatory and transient modes. The first experiments were done with a rough 25 $\mathrm{mm}$ diameter plate/plate configuration to avoid slipping on the wall. Then, each suspension was placed in a cone-plate geometry, with a cone diameter of $25 \mathrm{~mm}$, angle of $1.005^{\circ}$, and truncation of $51 \mu \mathrm{m}$. To prevent evaporation of isopropanol, a ring of silicone oil was spread around the sample on the plate to confine the suspension.

The structure of the fluid was elucidated by three kinds of dynamic tests: Strain sweeps from $\gamma=0.01 \%$ to $\gamma=100 \%$ strain at a fixed angular frequency $\omega$ of $1 \mathrm{rad} \cdot \mathrm{s}^{-1}$; frequency sweeps in the linear viscoelastic domain in the range $\omega=100 \mathrm{rad} \cdot \mathrm{s}^{-1}$ to $\omega=0.1 \mathrm{rad} \cdot \mathrm{s}^{-1}$ at $\gamma=1 \%$; time sweeps at a constant angular frequency of $1 \mathrm{rad} \cdot \mathrm{s}^{-1}$ and strain of $\gamma=0.1 \%$. The complex viscosity $\eta^{*}$ is calculated as follows from the storage modulus $G^{\prime}$ and dissipative modulus $G^{\prime \prime}$, with $\omega$ being the angular frequency:

$$
\left|\eta^{*}\right|=\frac{\sqrt{G^{\prime 2}+G^{\prime \prime 2}}}{\omega}
$$

Moreover, flow curves were determined by transient shear experi ments with the identical cone-plate geometry, at shear rates $\dot{\gamma}$ between 0.01 and $100 \mathrm{~s}^{-1}$. The shear viscosity $\eta$ is calculated from the ratio of the shear stress $\tau$ and the shear rate $\dot{\gamma}$ :

$$
\eta=\frac{\tau}{\dot{\gamma}}
$$

\section{RESULTS AND DISCUSSION}

Evidence of Chemical Treatment on the Surface: SEM, FTIR, and XPS. Figure 1 presents a SEM image of pristine $\mathrm{h} B N$. The platelets form layered crystalline sheet like particles with irregular shapes and sizes. Some of them are aggregated, resulting in a fluffy solid at the macroscopic scale. The h BN samples were observed by SEM after treatments; no significant change was noticed, as seen in the Supporting Information. 


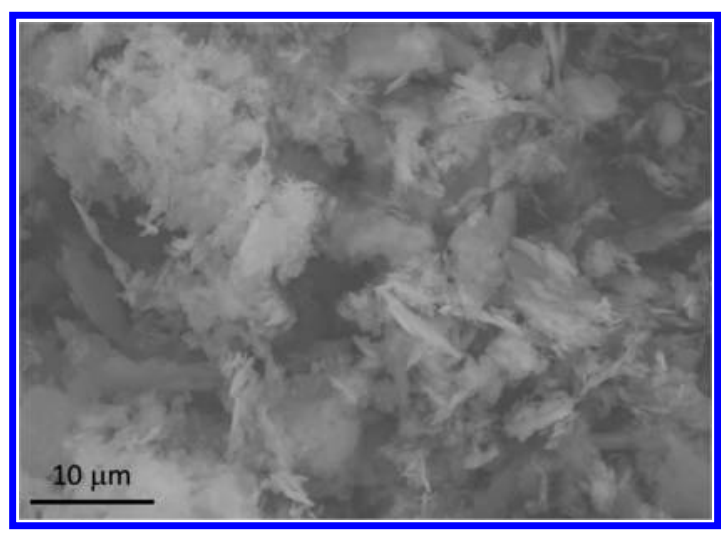

Figure 1. SEM photograph of pristine $\mathrm{h}$ BN platelets $($ scale $\times 2000)$

FTIR spectra of $\mathrm{h} \mathrm{BN}$ were registered after the different treatments, as seen in the Supporting Information. On all spectra, two strong absorption bands, characteristic of h BN structure, are seen at $\sim 1380$ and $763 \mathrm{~cm}^{-1}$, which are attributed to in plane $\mathrm{B}-\mathrm{N}$ stretching and out of plane $\mathrm{B}-\mathrm{N}$ bending, respectively. A weak absorption band at $3445 \mathrm{~cm}^{-1}$ is generally ascribed to $\mathrm{O}-\mathrm{H}$ stretching vibrations of the hydroxyl groups attached to defects along the edges of $h \mathrm{BN}$ due to washing in water. ${ }^{11,14,37}$ Here, no obvious spectral difference between treated, calcinated, and raw (pristine) samples was identified by FTIR. As mentioned by Zhi, ${ }^{12}$ infrared spectroscopy was found to be ineffective to study the chemically activated surface of boron nitride because the peaks of the species bonded overlap those of water and h BN itself.

Surface chemical composition on a few nanometers deep of the treated $\mathrm{h} \mathrm{BN}$ particles was quantified by $\mathrm{X}$ ray photo electron spectroscopy (XPS), and the results are presented in atomic percentage in Table 1 . The surface composition

Table 1. Chemical Composition in Atomic Percentage of Calcinated h BN (Cal), NaOH Treated h BN (NaOH), $\mathrm{HNO}_{3}$ Treated h BN $\left(\mathrm{HNO}_{3}\right)$, and $\mathrm{HNO}_{3}+\mathrm{H}_{2} \mathrm{O}_{2}$ Treated h BN $\left(\mathrm{HNO}_{3}+\mathrm{H}_{2} \mathrm{O}_{2}\right)$ Determined by XPS

\begin{tabular}{lcccc} 
& \multicolumn{4}{c}{ atomic percentage } \\
\cline { 2 - 5 } \multicolumn{1}{c}{ sample } & $\mathrm{B}$ & $\mathrm{C}$ & $\mathrm{N}$ & $\mathrm{O}$ \\
$\mathrm{Cal}$ & 40.5 & 16.0 & 38.6 & 4.9 \\
$\mathrm{NaOH}$ & 38.8 & 19.4 & 36.8 & 5.1 \\
$\mathrm{HNO}_{3}$ & 40.1 & 16.5 & 38.6 & 4.8 \\
$\mathrm{HNO}_{3}+\mathrm{H}_{2} \mathrm{O}_{2}$ & 37.7 & 20.6 & 36.0 & 5.7 \\
\hline
\end{tabular}

comprises different chemical elements: boron (B), nitrogen $(\mathrm{N})$, oxygen $(\mathrm{O})$, and carbon $(\mathrm{C})$. It was determined that at the particle surface, whatever the treatment, $\mathrm{B} / \mathrm{N}$ atomic ratios are close to 1 , in accordance with the stoichiometry of the $h$ $\mathrm{BN}$ structure. The presence of $\mathrm{C}$ and a part of $\mathrm{O}$ is due to the absorption of organic atmospheric pollutants such as hydro carbons and carbonyl compounds that can affect the surface energy of the particles. ${ }^{39}$ It was shown that the wettability of $h$ $\mathrm{BN}$ increases gradually to a saturated stable value in air due to the spontaneous adsorption of airborne hydrocarbons. ${ }^{40}$

The deconvolution of high resolution spectra of a chemical element gives information on its chemical environment such as the nature of bonds formed and the relative percentage of each chemical function. The XPS curves are presented in the Supporting Information. The boron B 1s core level analysis obtained from XPS for the treated $\mathrm{h} B N$ particles is presented in Table 2. In all cases, the B 1s spectrum can be fitted by three peaks: a main one at around $190.3 \mathrm{eV}$ assigned to $\mathrm{B}-\mathrm{N}$ bonds,

Table 2. Deconvolution of High Resolution Spectra B 1s with Their Corresponding Position and Area Percentage for Calcinated h BN (Cal), NaOH Treated h BN ( $\mathrm{NaOH})$, $\mathrm{HNO}_{3}$ Treated h BN $\left(\mathrm{HNO}_{3}\right)$, and $\mathrm{HNO}_{3}+\mathrm{H}_{2} \mathrm{O}_{2}$ Treated h BN $\left(\mathrm{HNO}_{3}+\mathrm{H}_{2} \mathrm{O}_{2}\right)$ Determined by XPS

\begin{tabular}{|c|c|c|c|c|c|c|}
\hline \multirow[b]{3}{*}{ sample } & \multicolumn{6}{|c|}{ B $1 \mathrm{~s}$} \\
\hline & \multicolumn{2}{|c|}{$\mathrm{B} \mathrm{N}$} & \multicolumn{2}{|c|}{$\mathrm{N} B \mathrm{O}$} & \multicolumn{2}{|c|}{$\mathrm{B} \mathrm{OH}$} \\
\hline & $\begin{array}{c}\text { position } \\
(\mathrm{eV})\end{array}$ & $\begin{array}{l}\text { area } \\
(\%)\end{array}$ & $\begin{array}{c}\text { position } \\
(\mathrm{eV})\end{array}$ & $\begin{array}{c}\text { area } \\
(\%)\end{array}$ & $\begin{array}{c}\text { position } \\
(\mathrm{eV})\end{array}$ & $\begin{array}{l}\text { area } \\
(\%)\end{array}$ \\
\hline Cal & 190.33 & 90.4 & 191.50 & 7.3 & 192.20 & 2.4 \\
\hline $\mathrm{NaOH}$ & 190.26 & 95.4 & 191.50 & 4.1 & 192.20 & 0.5 \\
\hline $\mathrm{HNO}_{3}$ & 190.34 & 91.4 & 191.50 & 8.0 & 192.20 & 0.6 \\
\hline $\mathrm{HNO}_{3}+\mathrm{H}_{2} \mathrm{O}_{2}$ & 190.25 & 91.9 & 191.40 & 6.8 & 192.10 & 1.3 \\
\hline
\end{tabular}

a second one at around $191.5 \mathrm{eV}$ attributed to boron atoms simultaneously bonded to nitrogen and oxygen $(\mathrm{N}-\mathrm{B}-\mathrm{O})$, and a third one of weak intensity at around $192.2 \mathrm{eV}$ ascribed to $\mathrm{B}-\mathrm{OH}$ bonds. ${ }^{41-43}$ These results show that the treatments induce hydroxylation occurring at the surface of $\mathrm{h} B N$ particles but in a small amount. It must be noted that the hydroxyl groups $-\mathrm{OH}$ are covalently attached to some of the boron atoms situated on the edges of platelets ${ }^{32}$ during the different treatments. The highest hydroxyl concentration, corresponding to $2.4 \%$ of boron atoms functionalized, is obtained after calcination, followed by $\mathrm{HNO}_{3}+\mathrm{H}_{2} \mathrm{O}_{2}$ treatment leading to $1.3 \%$, and finally at 0.6 and $0.5 \%$ for $\mathrm{HNO}_{3}$ and $\mathrm{NaOH}$ treatments, respectively.

Effect of Chemical Treatment on the Stability of Suspensions. The stability of low concentrated (2 vol \%) suspensions in isopropanol and water has been followed with time. Figure 2 shows that, as early as 1 day, the raw particles in isopropanol have begun to settle down. For the calcinated and treated particles, the suspensions are stable after 1 day, whereas, after 14 days, the suspensions of the particles treated with $\mathrm{HNO}_{3}$ present the transparent phase above and the particles have settled down the bottle. After 28 days, the suspension of the particles treated with $\mathrm{HNO}_{3}+\mathrm{H}_{2} \mathrm{O}_{2}$ still seems homogeneous. The calcinated particles and those treated with $\mathrm{NaOH}$ have slightly begun to settle down after 28 days.

Figure 3 shows the low concentrated suspensions in water. Raw, calcinated, and treated $\mathrm{h} \mathrm{BN}$ particles have begun to settle down as early as 1 day. As the difference between 14 and 28 days is not obvious, the settling of particles evolved slowly after 14 days. All of the bottles present a floating phase on the top; it corresponds to the particles trapped in air bubbles forming capillary bridges. In the middle of the bottles, the phase is transparent. Lastly, at the bottom, the thickness of the sedimented phase depends on each treatment. The higher thickness is reached with the calcinated particles, for which the level does not change much after 1 day. Only the phase just above became clearer and clearer with time, corresponding to the settling of fines. The evolution of the other suspensions is slower, and the final thickness of sediment is lower. However, it is difficult to make a comparison with the raw particles, since the particles are stuck on the glass wall instead of going down. An explanation could be that the particles are initially highly hydrophobic, possibly due to an organosilane treatment done by the supplier. For this reason, the $\mathrm{h} B N$ particles tend toward 


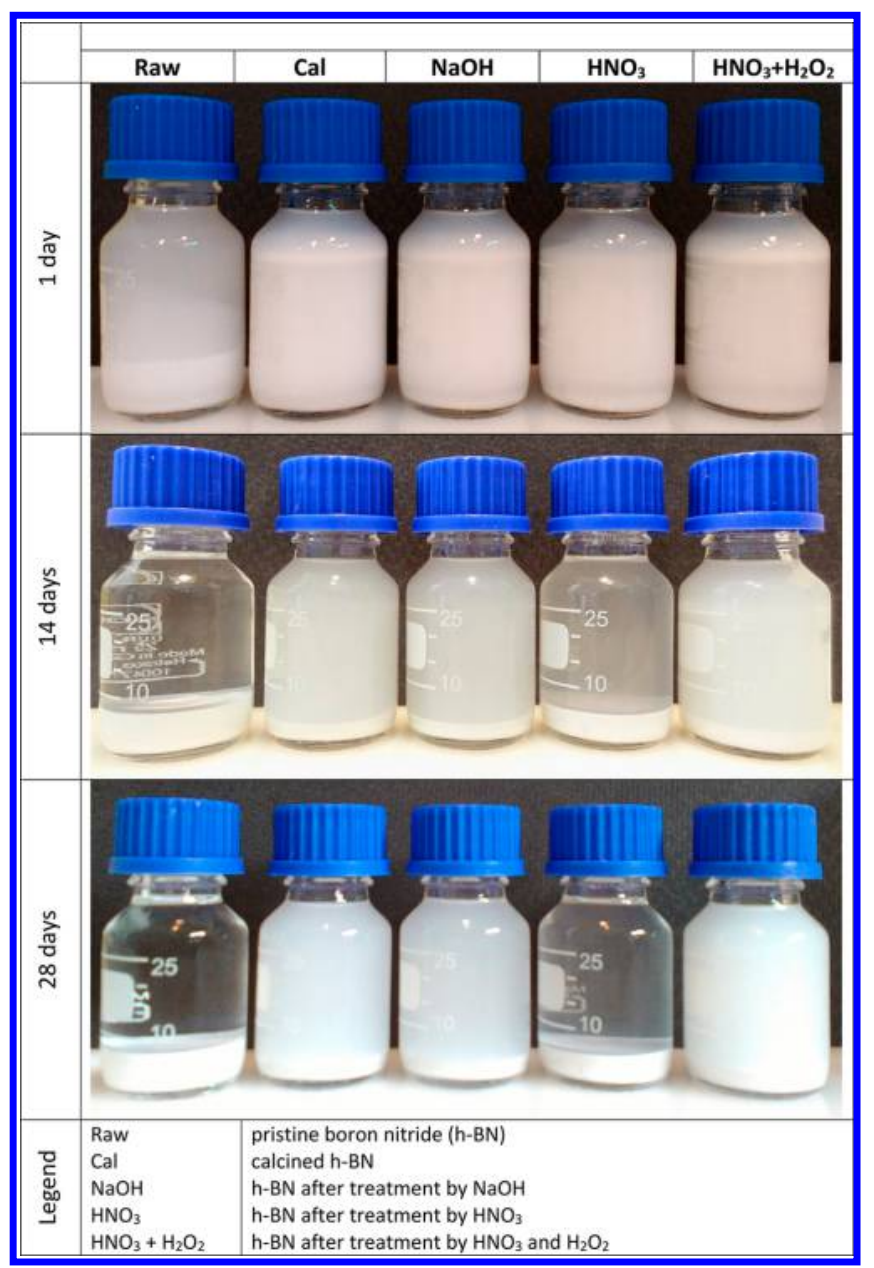

Figure 2. Photos of $2 \mathrm{vol} \% \mathrm{~h} \mathrm{BN}$ suspensions in isopropanol.

minimizing the contact surface with water. On the contrary, the treated particles appear less hydrophobic, due to introduction of hydroxyl groups on the edges of the platelets.

The visual observation is only possible for low concentrated suspensions. At higher concentration, the particles interact hydrodynamically, hindering their settling rate.

For a deeper understanding of the settling of high concentrated suspensions, multiple light scattering was performed for $\mathrm{h} \mathrm{BN}$ suspensions in water with particles treated by calcination, acidic and oxidizing treatment. The back scattered light was normalized by the initial intensity, so that $\Delta R(\%)=R(t) / R_{\mathrm{i}}$, with $R(t)$ the intensity registered at each time lap and $R_{\mathrm{i}}$ the intensity at $t=0$. Figure 4a corresponding to the calcinated particles shows a slight evolution of $\Delta R$ with time. Also, the curve is flat, indicating that the concentration and size repartition of $\mathrm{h} B N$ platelets is homogeneous all along the height of the vial. No change happens for more than 9 days. This stability could stem from the repulsion between the hydroxyl $(-\mathrm{OH})$ groups created on the $\mathrm{h} \mathrm{BN}$ surfaces.

On the contrary, more changes are visible on the backscattered light for the suspensions of particles treated by acidic and oxidizing treatment. In Figure $4 b$, the top of the vial is subjected to a decrease of light intensity, that is to say, a decrease in particle concentration for about 2 days, balanced by a higher intensity at a lower height of the vial. After 2 days, the particles move to the top of the vial, as seen in Figure 3 for the low concentrated suspension, as measured by the increase of the signal intensity. The particles treated by oxidizing

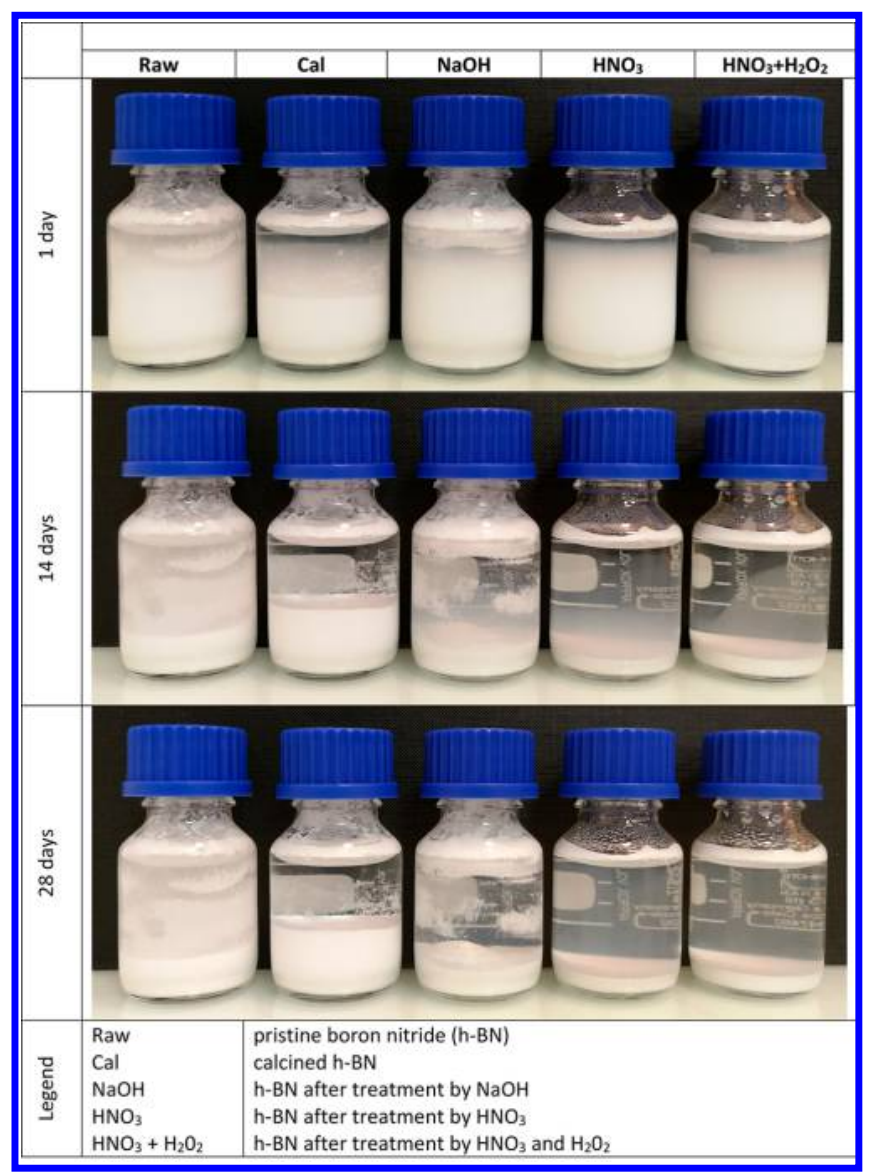

Figure 3. Photos of $2 \mathrm{vol} \% \mathrm{~h} \mathrm{BN}$ suspensions in water.

treatment move along the height of the vial from the beginning of the test to the end at 10 days. Indeed, in Figure $4 c$, the 5 $\mathrm{mm}$ highest zone and the $2 \mathrm{~mm}$ lowest zone of the vial undergo important motion of particles, with settling and floating of particles. The floating phase on the top corresponding to particles trapped in air bubbles evolves with time: when the air bubbles are broken, the capillary bridges fall down, and the particles settle spontaneously in the solvent. The same behavior was observed for low concentrated suspensions in Figure 3.

From the previous data, the speed of settling was studied by plotting in Figure 5 the backscattered light $\Delta R$ in the clarified zone, in other words, the $4 \mathrm{~mm}$ highest zone of the vial where the most changes appear, versus time for the first 3 days. Indeed, the clarified zone is more representative of the settling of the particles. Again, the particles treated by calcination are very stable, while the particles treated by oxidizing and acidic treatment move down, as proved by the decrease of $\Delta R$. The speed of settling is the highest for the particles treated by $\mathrm{HNO}_{3}$; this agrees with Figure 3, admittedly for low concentrated suspension.

The higher stability for calcinated particles in water could be explained by the grafting of more $-\mathrm{OH}$ groups on the edges of platelets: the platelets repulse each other, such as observed in electrically charged mineral suspensions. ${ }^{44}$ The rheological behavior of these suspensions is typically like that of a highly viscous liquid or a gel. The aim of the next section is to elucidate the rheological behavior of treated h BN suspensions.

Rheological Measurements. The rheological behavior of suspensions is dependent to a large extent on the shape, the 


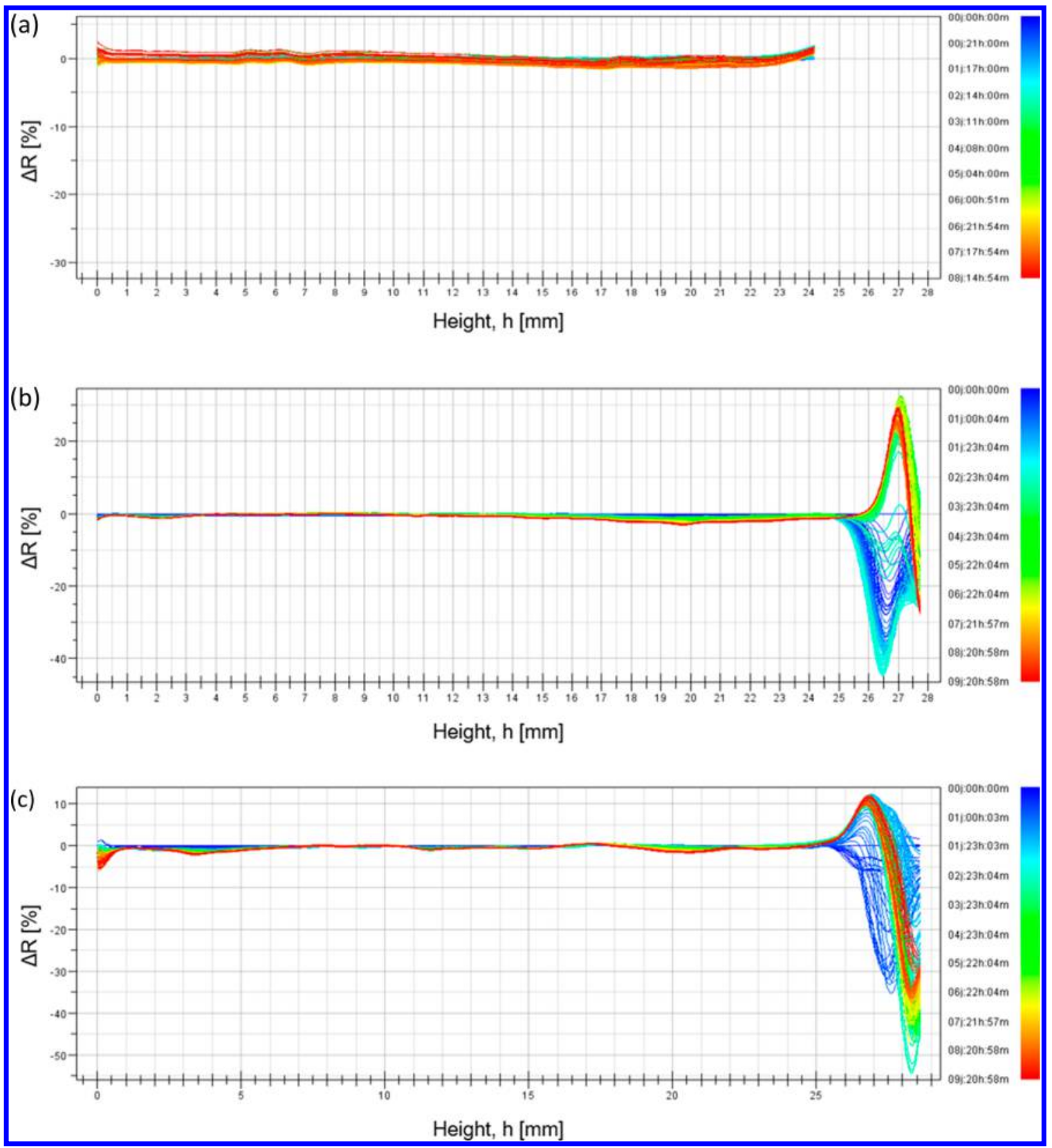

Figure 4. Normalized backscattered light for $12 \mathrm{vol} \% \mathrm{~h} \mathrm{BN}$ suspensions in water particles treated by (a) calcination, $(\mathrm{b}) \mathrm{HNO}_{3}$, and $(\mathrm{c}) \mathrm{HNO}_{3}+$ $\mathrm{H}_{2} \mathrm{O}_{2}$.

particle sizes, the particle-solvent interaction, and the particle-particle interaction. Rheological measurements were performed right after sonication to avoid sedimentation. Gravity effects and inhomogeneities in particle concentration due to sedimentation cannot be avoided for particle sizes greater than $1 \mu \mathrm{m} .^{38} \mathrm{We}$ assume that the gravity effect is insignificant for the duration of the test considering the kinetics of settling observed in Figures 2-5 whereas our particle size is centered at $2 \mu \mathrm{m}$, except for the suspensions of pristine (untreated) h BN, the latter were not studied by rheometry. Comparing the flow of pure solvent and suspensions, the presence of particles distorts the flow field and can therefore be expected to increase the energy dissipation during flow, and hence the viscosity.

Formation and Breakage of a Weak Gel. This section aims to elucidate the behavior of the highly concentrated h BN suspensions. For that, the suspension prepared with calcinated $\mathrm{h} \mathrm{BN}$ particles with a volume concentration of $14 \%$ in water was used.

Determination of the Gel Point. Figure 6 shows the strain sweeps from 0.01 to $100 \%$ performed at a fixed frequency of 1 $\mathrm{rad} \cdot \mathrm{s}^{-1}$ at $23{ }^{\circ} \mathrm{C}$ with a rough plate to prevent slipping. The experiments have been repeated at various gaps between 1000 and $300 \mu \mathrm{m}$. The storage $G^{\prime}$ and dissipative $G^{\prime \prime}$ moduli are constant with angular frequency and parallel to the $x$ axis for the smallest strains in Figure 6a; then, their crossover at 10 and $14 \%$ indicates that the organization of particles is broken. This point marks the limit of the linear viscoelastic domain. The behavior of $\mathrm{h} B N$ suspensions evokes concentrated ceramic suspensions in water, for which the particle-particle interactions are so highly repulsive that the rheological response is like that of a gel. Right after the end of the first 


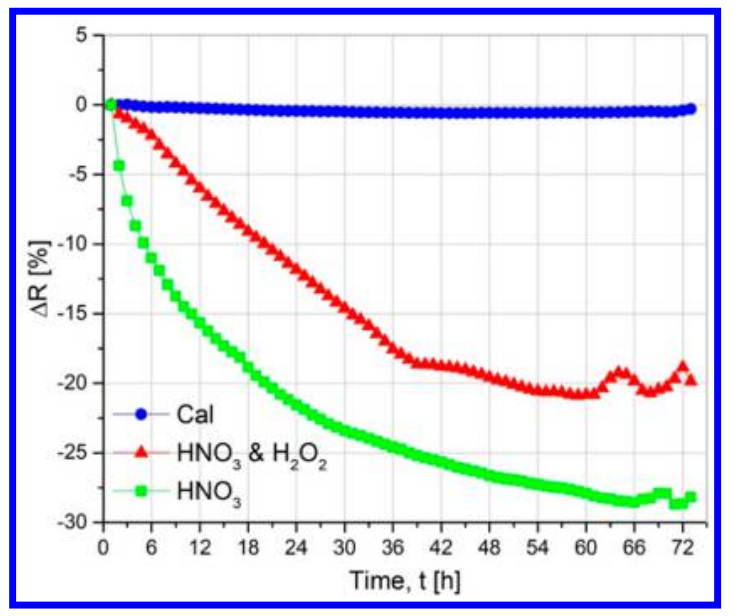

Figure 5. Normalized backscattered light in the clarified zone for 12 vol \% $\mathrm{h} \mathrm{BN}$ suspensions in water.

test, the second one is started under the same conditions on the same sample: The $G^{\prime}$ values obtained during the first and second tests are very close to each other, while the $G^{\prime \prime}$ values do not overlap at the lowest strains. A hypothesis is that the viscoelastic recovery is longer than the time lap between the end of the first cycle and the beginning of the second one. The $G^{\prime \prime}$ for the second test becomes equal to $G^{\prime \prime}$ for the first test when $G^{\prime}$ drops so much that the gel like structure begins to disorder. It is reasonable to assume that, below $1 \%$ strain, any mechanical solicitation has no effect on the structure of the gel and the delayed recovery takes place during the second cycle: when the structure is broken due to high strain, it recovers fast. Figure $6 \mathrm{~b}$ plots the stress registered during this test, versus strain. The maximum of this curve indicates that, in dynamic mode, the yield stress from which the gel begins to break is about $16000 \mathrm{~Pa}$.

Maximum Strain before Breakage. The transient shear test was performed step by step at a fixed shear rate $\dot{\gamma}$ from 0.01 to $100 \mathrm{~s}^{-1}$. For each $\dot{\gamma}$, the points are recorded every $1 \mathrm{~s}$ until stabilization for at least the duration $t$ such as $\dot{\gamma} \times t \geq 5$. The results of shear stress versus shear rate are reported in Figure 7. For shear rate higher than $1 \mathrm{~s}^{-1}$, the stress drastically drops to about $1000 \mathrm{~Pa}$. The first part of the curve matches the behavior of a Bingham fluid with a yield stress of about $5900 \mathrm{~Pa}$. Above

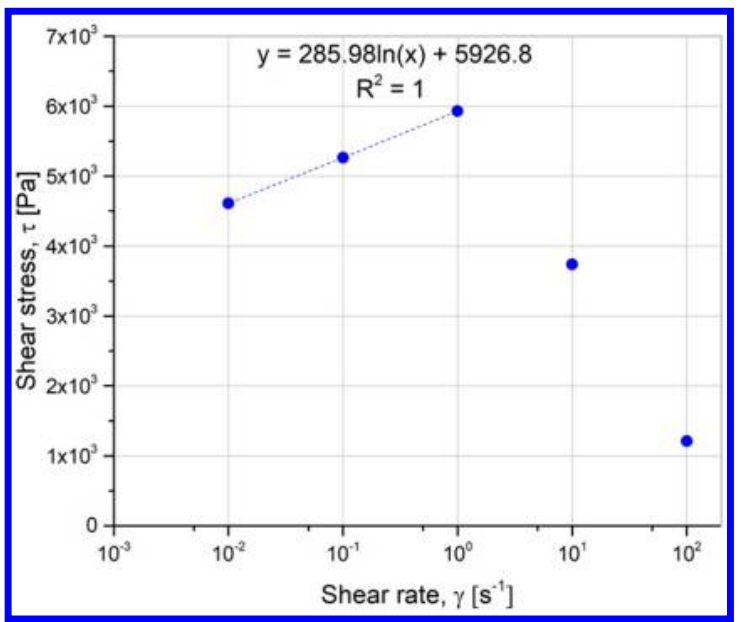

Figure 7. Stress-strain curve for transient flow from 0.01 to $100 \mathrm{~s}^{-1}$ for $14 \mathrm{vol} \%$ suspension with calcinated particles.

the limit of $1 \mathrm{~s}^{-1}$, the structure is broken and the stress falls down.

Hence, when comparing the stress for destructuring the gel under permanent and dynamic conditions, the values of 5900 and $16000 \mathrm{~Pa}$ are measured, respectively. This difference could be explained by the fact that, in continuous shear, the solicitation forces the gel to break, while the conditions are smoother under dynamic conditions.

Time for the Gel to Recover. As seen previously, the structure formed by the particle-particle interaction is broken when the shear rate is higher than $1 \mathrm{~s}^{-1}$. Now, the time of recovery will be determined. For that, a preshear at $100 \mathrm{~s}^{-1}$ is applied for $5 \mathrm{~s}$ to break the organization of particles and oscillations at small amplitude of $0.1 \%$ and $1 \mathrm{rad} \cdot \mathrm{s}^{-1}$ are applied to follow the recovery of the gel. The same procedure was applied twice. Figure 8 shows $G^{\prime}$ and $G^{\prime \prime}$ with time for the two cycles. Right after the preshear and for the 10 first seconds, the behavior is liquid like with $G^{\prime \prime}>G^{\prime}$; then, the tendency is rapidly inverted, and the behavior tends to a solid like one with $G^{\prime}>G^{\prime \prime}$, showing that the particles have recovered a high level of organization in about $10 \mathrm{~s}$.

Conclusion. From this section, the behavior of concentrated h BN suspensions is assimilated to that of a self structured

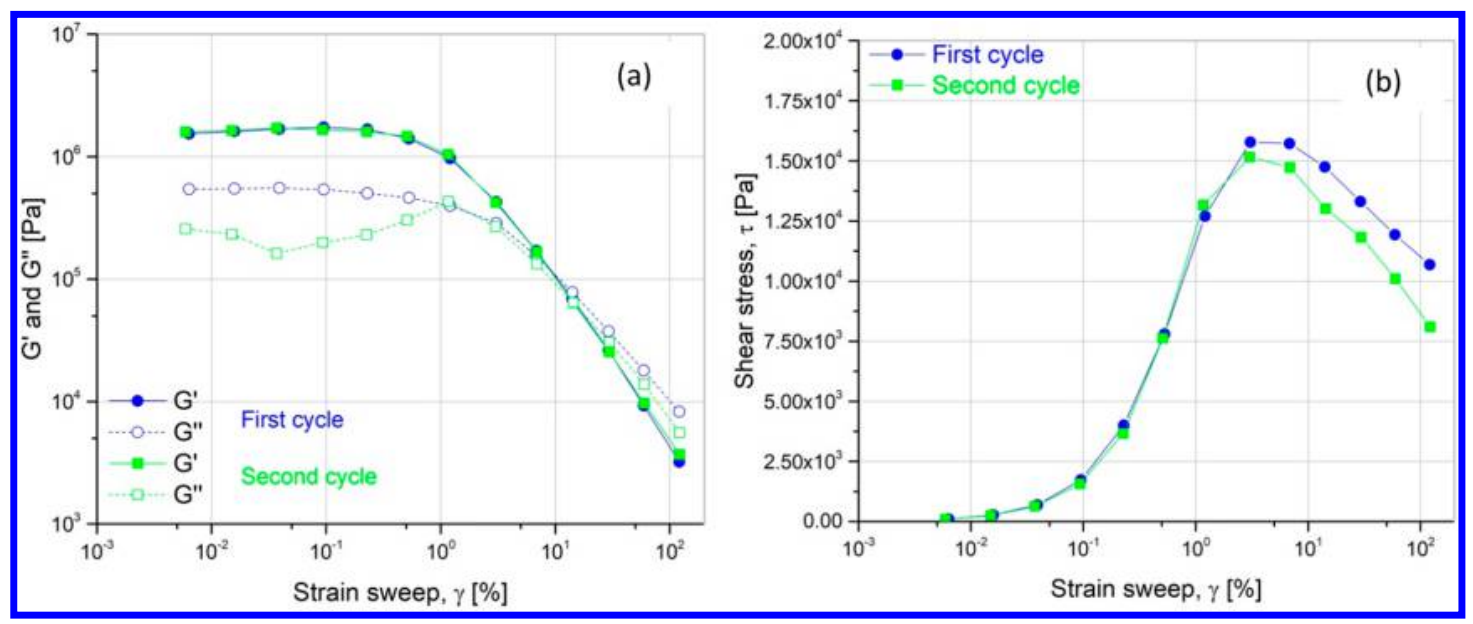

Figure 6. Successive strain sweeps at $1 \mathrm{rad} \cdot \mathrm{s}^{-1}$ for $14 \mathrm{vol} \%$ suspension with calcinated particles: (a) $G^{\prime}$ and $G^{\prime \prime}$ versus strain; (b) stress versus strain. 


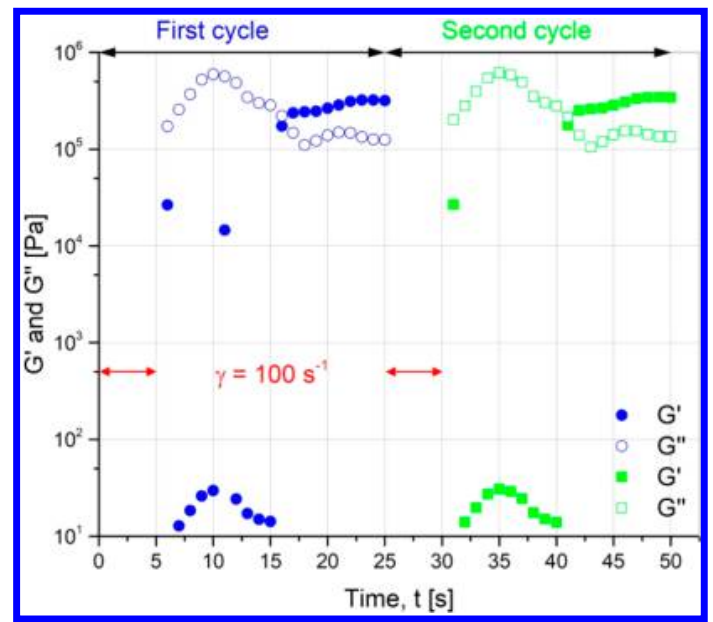

Figure 8. Time sweeps at $0.1 \%$ and $1 \mathrm{rad} \cdot \mathrm{s}^{-1}$ after a preshear at 100 $\mathrm{s}^{-1}$ for $5 \mathrm{~s}$ for $14 \mathrm{vol} \%$ suspension with calcinated particles.

liquid formed by the particle-particle interaction. The organization is broken at shear rate higher than $1 \mathrm{~s}^{-1}$ in transient flow or at a strain rate higher than $10 \%$ in dynamic solicitations. The time needed for the structure to recover is 10 s.
Study of Suspensions Using Transient Flow Measurements. The highly concentrated suspensions in water with a volume fraction of $12,14,16$, and $18 \%$ have been studied by rheometry through transient flow. The flow curves $(\eta=f(\dot{\gamma}))$ are shown in Figure 9. At low volume fraction, the suspension viscosity is slightly greater than that of the solvent (not shown), while, at high volume content (12-18\%), the viscosity shows pronounced shear thinning, with $\dot{\gamma}^{-1}$ dependency. The shear thinning behavior is observed in suspensions when the shear rate $(\dot{\gamma})$ is high enough to disturb from equilibrium the particle position. ${ }^{45}$ The motion of each particle is governed by hydrodynamic forces, Brownian motion $\left(k_{\mathrm{B}} T\right.$ with $k_{\mathrm{B}}$ being the Boltzmann constant and $T$ the temperature), and gravity effects. Any motion of particles is opposed to frictional forces of particle-particle interactions. At high concentration, the motion of particles is limited, since the frictional forces are very high and a range of attractive and repulsive forces maintain it at a static position. Once particle-particle contacts are formed, they are released by Brownian agitation in a so long time that particle motion which in principle would lead to rearrange ments is suppressed. A Newtonian plateau is expected at low shear rate if the diffusion of the particle would be faster than the time scale of the disturbance caused by the flow rate. This ratio is related to the Peclet number, expressed as below:
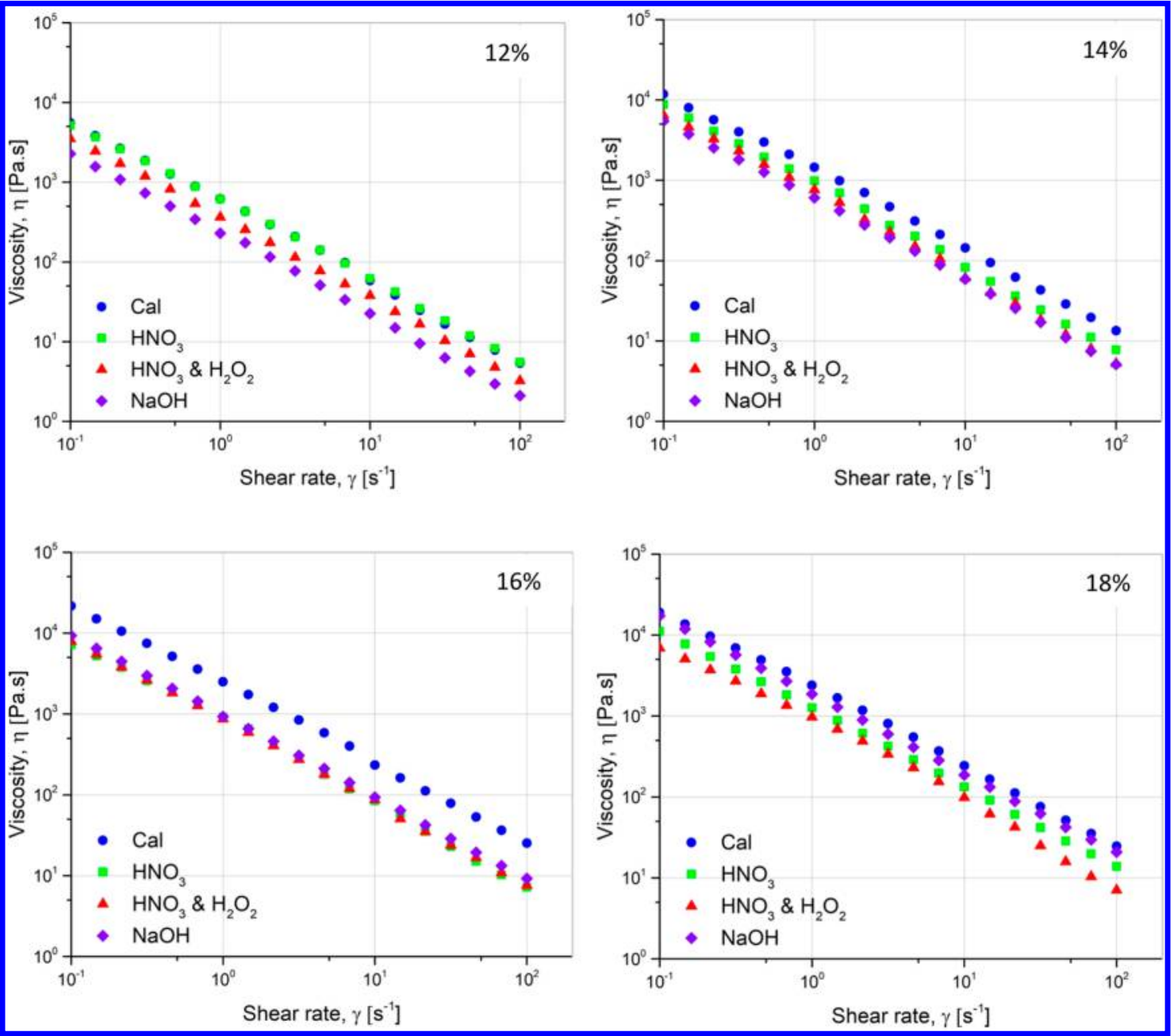

Figure 9. Flow curves for suspensions in water. 


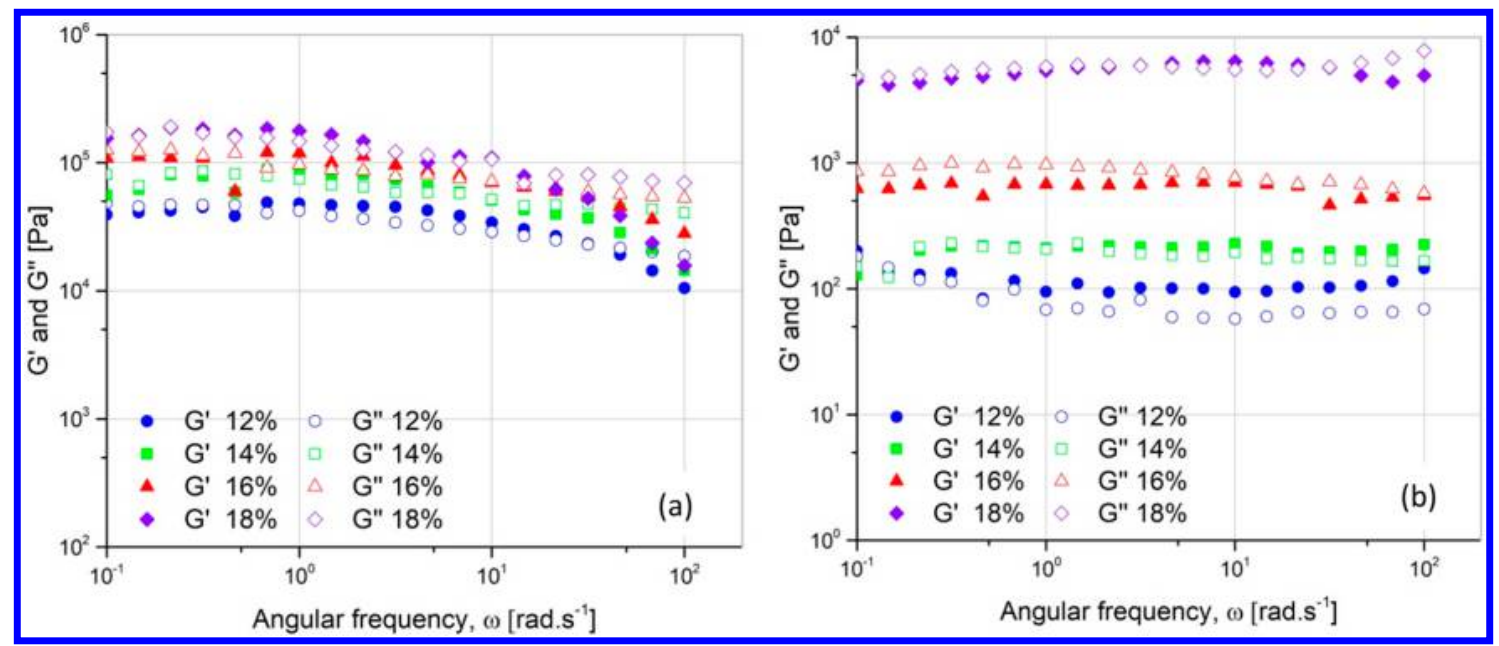

Figure 10. Storage $G^{\prime}$ and loss $G^{\prime \prime}$ moduli from frequency sweeps of suspensions at $23{ }^{\circ} \mathrm{C}$ for (a) $\mathrm{HNO}_{3}+\mathrm{H}_{2} \mathrm{O}_{2}$ treated $\mathrm{h} B N$ particles in water and (b) $\mathrm{HNO}_{3}+\mathrm{H}_{2} \mathrm{O}_{2}$ treated $\mathrm{h} \mathrm{BN}$ particles in isopropanol.

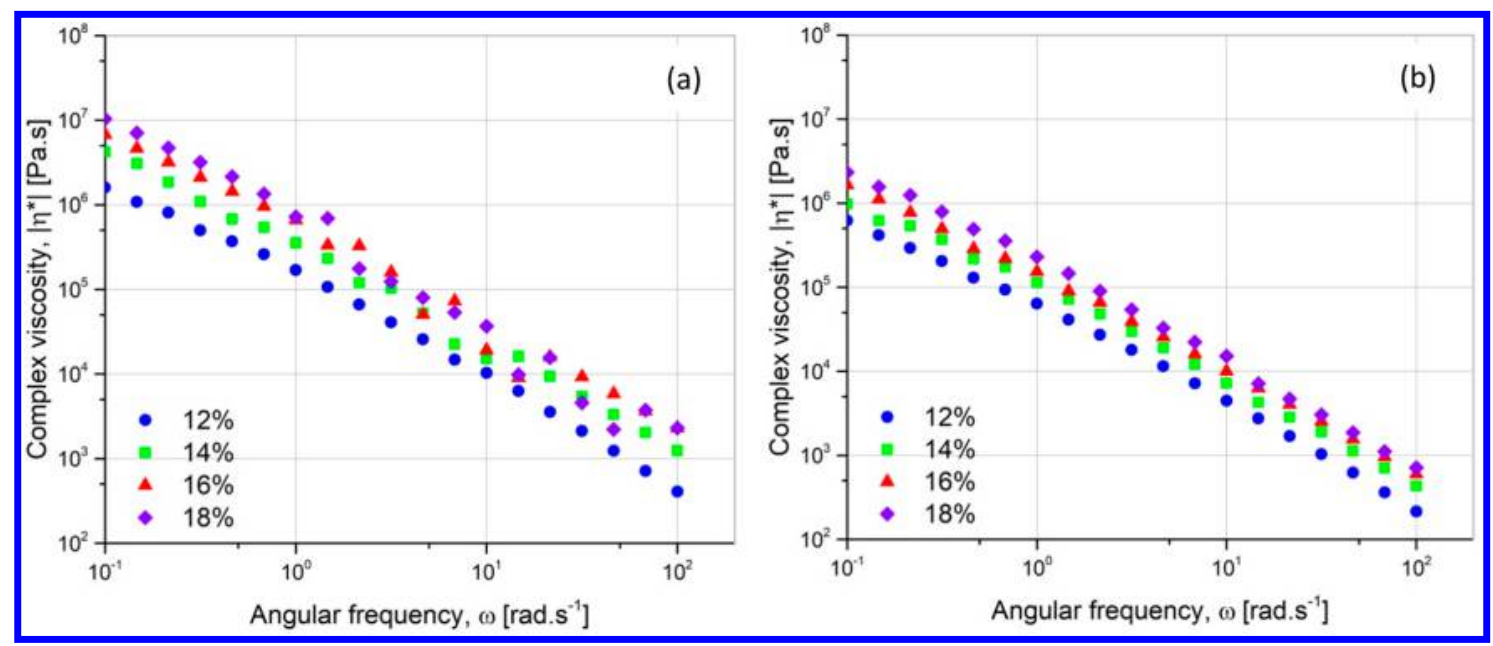

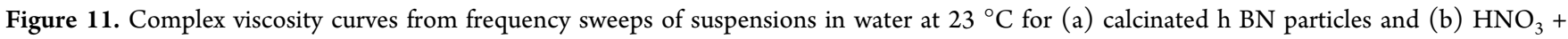
$\mathrm{H}_{2} \mathrm{O}_{2}$ treated h BN particles.

$$
P e=\frac{\eta_{\mathrm{s}} \dot{\gamma} a^{3}}{k_{\mathrm{B}} T}
$$

with $\eta_{\mathrm{s}}$ the solvent viscosity and the particle diameter. In our case, the shear rate for which the diffusion time allows the particles to rediscover their equilibrium state is nearly $10^{-12}$ $\mathrm{s}^{-1}$. For this reason, the Newtonian plateau is not visible in Figure 9 in which the lowest shear rate is $10^{-1} \mathrm{~s}^{-1}$. Identically, a shear yield stress often appears at low shear for highly concentrated ceramic suspensions ${ }^{44}$ submitted to continuous flow.

In Figure 9, the comparison of each treatment from the viscosity curves is uncertain, since the gap between the curves is in the same order of magnitude of the uncertainty of measurements. It has been demonstrated in Figure 6 and Figure 7 that the continuous shear breaks the organization of particles; that is why the suspensions have been characterized by dynamic mode in the next section.

Study of h-BN Suspensions Using Dynamic Measurements. The storage $G^{\prime}$ and loss $G^{\prime \prime}$ moduli of suspensions of oxidized h BN particles in water and in isopropanol are presented in Figure 10. There is a little frequency dependence of $G^{\prime}$ and $G^{\prime \prime}$, and the loss modulus $G^{\prime \prime}$ is very close to the storage modulus $G^{\prime}$. All of the curves have two crossovers. This behavior is representative of a strongly flocculated gel. ${ }^{38}$ As expected, the $G^{\prime}$ and $G^{\prime \prime}$ increase with the particle concentration. The comparison of $G^{\prime}$ and $G^{\prime \prime}$ for the suspensions in water in Figure 10a and isopropanol in Figure $10 \mathrm{~b}$ indicates higher $G^{\prime}$ and $G^{\prime \prime}$ for the suspension in water. Hence, the higher interaction between water and $-\mathrm{OH}$ groups held by the h BN surface could result in a higher level of solvent-particle repulsion.

Figure 11 shows the complex viscosity versus angular frequency for suspensions made from boron nitride particles in water at high concentrations from 12 to $18 \mathrm{vol} \%$. Similar to the transient flow, the complex viscosity shows pronounced shear thinning, with $\omega^{-1}$ dependency. The same behavior was noticed for the suspensions made from all treated $h \mathrm{BN}$ particles (see the Supporting Information), all with a $\omega^{-1}$ dependency.

The reduced viscosity $\eta_{\mathrm{r}}$ at $1 \mathrm{rad} \cdot \mathrm{s}^{-1}$, the ratio of the complex viscosity of suspensions over the viscosity of the solvent, is plotted versus solid fraction in Figure 12 in log linear scale. For all treatments, the reduced viscosity of suspensions is higher for suspensions in water compared to suspensions in isopropanol. This is explained by the fact that 

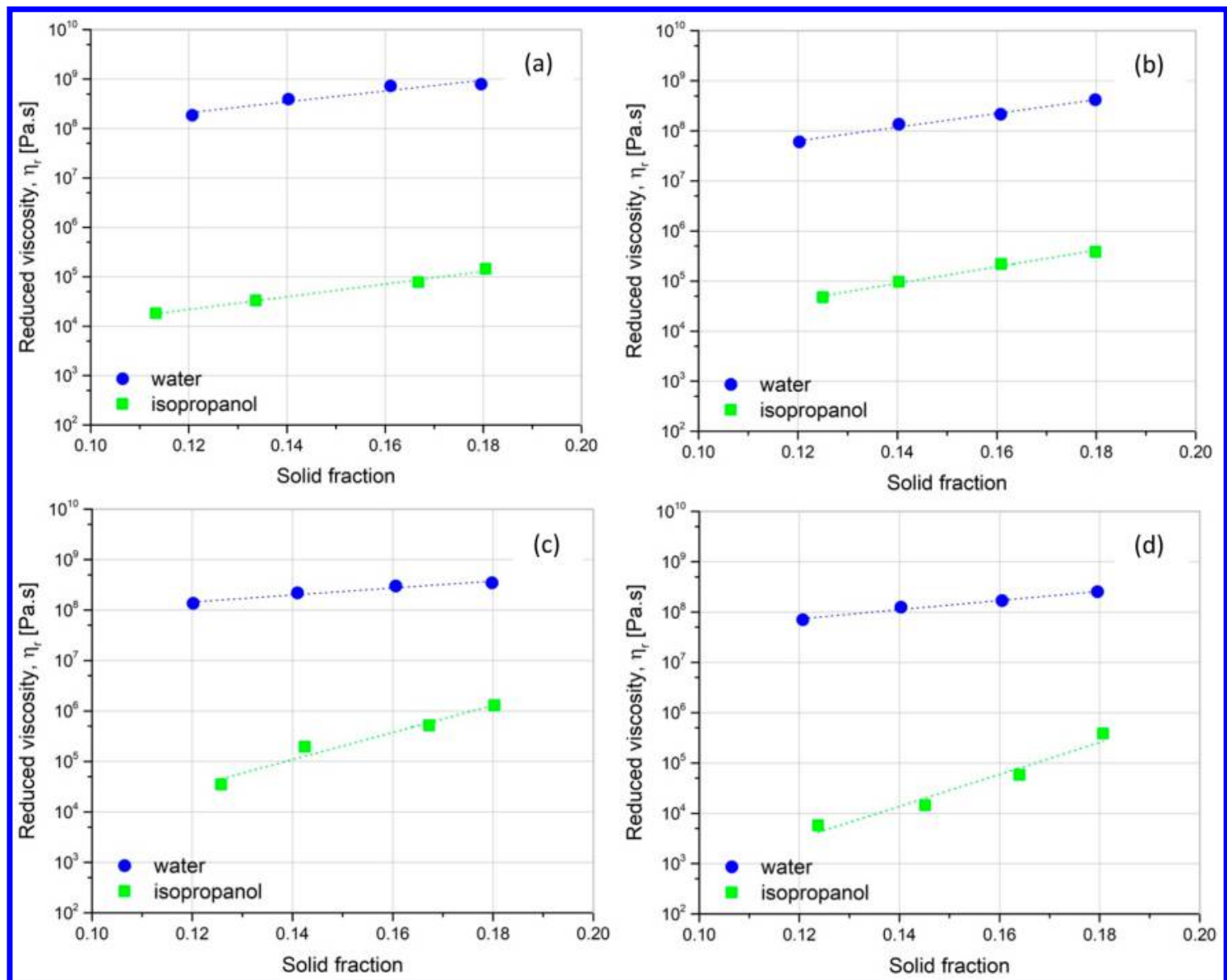

Figure 12. Relative viscosity at $1 \mathrm{rad} \cdot \mathrm{s}^{-1}$ of suspensions of treated $\mathrm{h} \mathrm{BN}$ at $23{ }^{\circ} \mathrm{C}$ : (a) calcinated $\mathrm{h} \mathrm{BN}$; (b) $\mathrm{NaOH}$ treated h $\mathrm{BN}$ (c) $\mathrm{HNO}_{3}$ treated h BN; (d) $\mathrm{HNO}_{3}+\mathrm{H}_{2} \mathrm{O}_{2}$ treated h BN.

the polarity of water is higher than those of isopropanol: the hydroxyl polar bond of $\mathrm{h} \mathrm{BN}-\mathrm{OH}$ facilitates the dispersion of platelets in solvents with higher polarity. Besides the polarity, water has a higher protic (acidic) character than isopropanol, meaning the molecules readily donate labile protons: the $\mathrm{p} K_{\mathrm{a}}$ of water is 14 , against 17.1 for isopropanol. As a consequence, more protons will come at the closest surface of $h \mathrm{BN}$ particles in water, increasing the repulsive intensity of particles in water. Hence, the interparticle forces are governed by the sum of the attractive van der Waals and the repulsive electrical double layer forces (DLVO theory) and hydration, hydrophobic, and attractive depletion forces. Colloidal suspensions are stabilized by promoting a net repulsive interparticle force. ${ }^{45}$ The intensity of repulsion forces is observed at macroscopic scale by an increase of suspension viscosity.

The variation of the reduced viscosity with concentration is expressed as $\log \eta_{\mathrm{r}}=\alpha \phi+\beta$, indicating a linear dependency in the volume concentration $(\phi)$ range of $0.12-0.18$. This is explained by the properties of $h \mathrm{BN}$ platelets: the $\mathrm{h} B N$ layers are linked to each other by out of plane hydrogen bonds so that the layers flow by sliding by one another.

For $\mathrm{h}$ BN particles calcinated and with basic treatment, the curves of suspensions in water and isopropanol are parallel to each other in Figure 12a and b. Oppositely, for acidic and oxidizing (nitric acid followed by hydrogen peroxide) treat ments, the slope of the line for the suspensions in isopropanol is higher in Figure 12c and d. Hence, the gap between the viscosity curves is large, to reach up to four decades in the case of oxidizing treatment for the volume fraction of 0.12 .

Whatever the treatment, the reaction induced by the treatments is summarized in Figure 13.

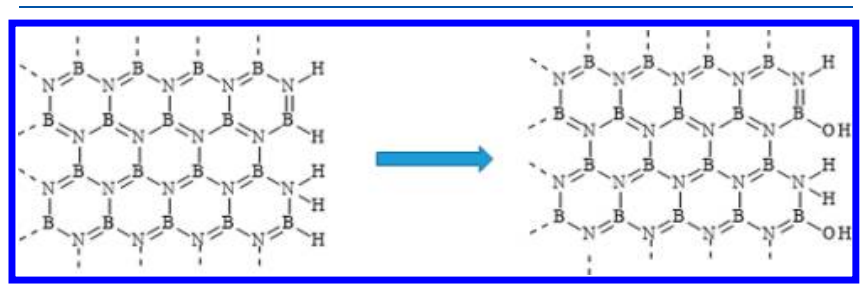

Figure 13. Scheme of change induced by the treatments.

Basal planes of $\mathrm{h} \mathrm{BN}$ are less susceptible to undergo chemical functionalization due to strong $\mathrm{B}-\mathrm{N}$ bonds in comparison to the edges. The hydroxyl groups $-\mathrm{OH}$ are more likely introduced on the edges of the platelets and more precisely on the boron atoms. ${ }^{32}$

Lastly, the comparison of the efficiency of treatments is presented in Figure 14. The reduced viscosity at $1 \mathrm{rad} \cdot \mathrm{s}^{-1}$ is plotted over solid fraction for (a) suspensions in water and (b) suspensions in isopropanol. As a reminder, the suspensions of raw particles have not been characterized by rheometry because their settling could not be neglected for the duration of the experiments.

For the suspensions in water, the rise of viscosity looks linear with the solid fraction. The highest viscosity is obtained for $\mathrm{h}$ 

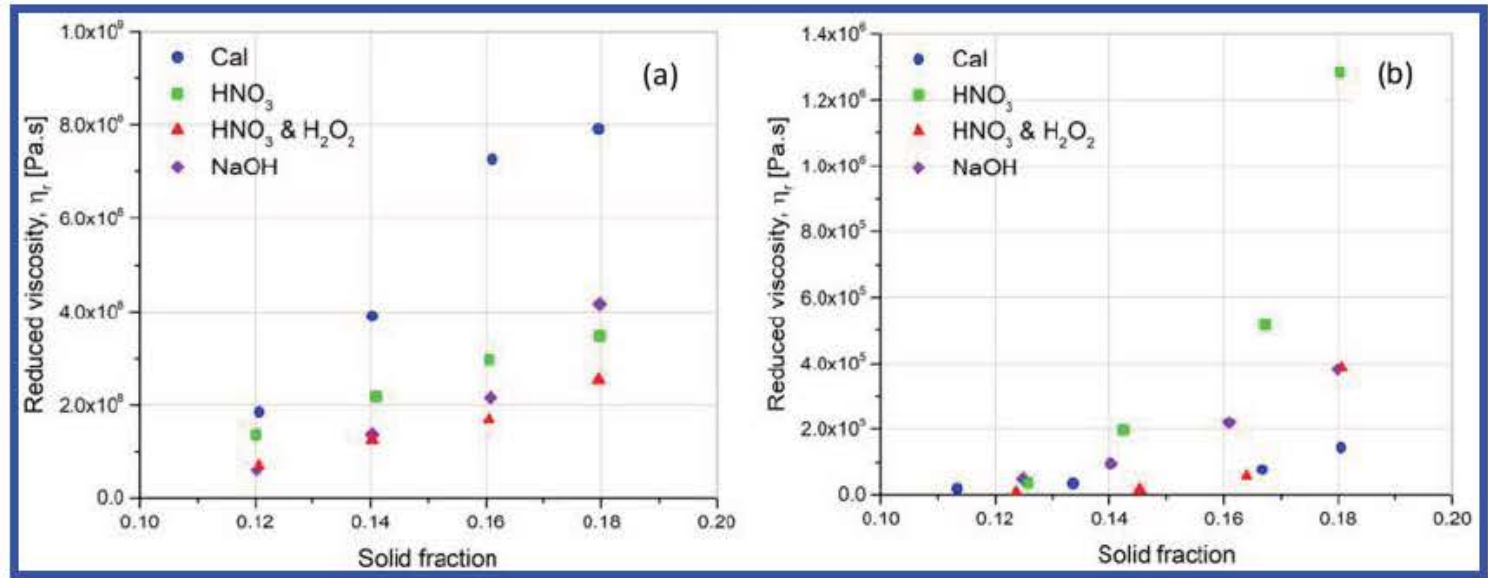

Figure 14. Viscosity of suspensions at $1 \mathrm{rad} \cdot \mathrm{s}^{-1}$ at $23{ }^{\circ} \mathrm{C}$ at various concentrations: (a) in water; (b) in isopropanol.

$\mathrm{BN}$ particles treated by calcination, indicating that the thermal treatment creates electronic charges, inducing more repulsive interactions between $\mathrm{h} \mathrm{BN}$ particles. The acidic treatment and then the basic and oxidizing treatment are less efficient to stabilize the suspensions in water by repulsive electrostatic interactions.

For the suspensions in isopropanol, the reduced viscosity increases exponentially with the $\mathrm{h} \mathrm{BN}$ solid fraction. The highest viscosity is obtained with the particles submitted to acidic treatment, followed by basic treatment and then oxidizing and calcination treatments. Despite a rapid settling observed in Figure 2 for the suspension made with acid treated particles, the final height of the sediment layer is the highest among the suspensions. The gel like behavior shown by rheometry at high concentration indicates that the particles self organize in a network. At low concentrations, these interactions will still occur; however, the volume fraction is probably too low to create a sample spanning network. In this scenario, aggregates of particles having a size larger than individual ones will settle at faster rates.

\section{CONCLUSION}

In conclusion, we have compared four treatments to select the one that increases most significantly the hydrophilicity of hexagonal boron nitride platelets. Various methods to activate the surface by introducing hydroxyl $(-\mathrm{OH})$ groups onto $2 \mu \mathrm{m}$ average diameter $\mathrm{h} \mathrm{BN}$ particles have been compared: calcination, basic, acidic, and oxidizing treatments. The boron sites in the $\mathrm{h} \mathrm{BN}$ lattice could be theoretically activated by oxidation which is expected to result in yielding hydroxyl groups at the $\mathrm{h} \mathrm{BN}$ surfaces. In order to determine the most efficient treatment, that is to say, for which the most $-\mathrm{OH}$ groups are grafted onto the surface, SEM, FTIR, XPS, sedimentation tests, multiple light scattering, and rheometry have been carried out. Besides the difficulty to quantify the number of $-\mathrm{OH}$ groups with FTIR and XPS, rheometry appears as a possible option to probe the surface alteration.

The rheometrical behavior of stable suspensions in water and isopropanol has been determined by studying their rheometrical behavior upon transient flow and dynamic tests. All of the suspensions demonstrate a gel like behavior at low strain thanks to self assembly of $\mathrm{h} \mathrm{BN}$ particles. Above $1 \%$ strain, the organization of particles falls down, resulting in a decrease of viscosity. The structure recovers fast in about $10 \mathrm{~s}$ at rest. Similarly to the transient flow, the complex viscosity shows pronounced shear thinning, with $\omega^{-1}$ dependency for all suspensions.

The comparison of the viscosity of the highly concentrated suspensions shows that the most efficient is the thermal treatment, for which the viscosity is the highest in water, an indication of a higher level of particle organization. For the suspensions in isopropanol, the higher viscosity is reached with the particles treated by nitric acid. The results obtained by rheometry agree with multiple light scattering experiments. The sedimentation tests have been carried out on the low concentrated suspensions. Even though they are easy to perform, the sedimentation tests are not appropriate to characterize the surface alteration of boron nitride platelets. Indeed, the conclusions are difficult to extract, since the settling rate as well as the height of the sediment layer must be analyzed. Both multiple light scattering and rheometry appear as efficient techniques to probe slight chemical alterations of hexagonal boron nitride platelets.

To conclude, the thermal treatment is more environmentally friendly than using strong acids or bases to introduce hydroxyl groups on hexagonal boron nitride particles. Subsequently, the hydroxylated $\mathrm{h}$ BN could be further modified by grafting the surface with a silane agent or other reactants to tailor the surface properties.

\section{ASSOCIATED CONTENT}

Additional SEM images, FTIR and XPS spectra, and viscosity curves for high concentrated suspensions (PDF)

\section{AUTHOR INFORMATION}

\section{Corresponding Author}

*E mail: fchabert@enit.fr.

\section{ORCID}

France Chabert: 0000000163094372

\section{Notes}

The authors declare no competing financial interest. 


\section{ACKNOWLEDGMENTS}

The authors thank Mr Jeremy Cohen from Formulaction company for performing multiple light scattering experiments, Mr Jérome Esvan from CIRIMAT UMR CNRS 5085 at the Université Fédérale de Toulouse for performing XPS experi ments, and $\operatorname{Pr}$ Nick Virgilio at the Chemical Engineering Department at Ecole Polytechnique de Montreal, Canada, for helpful discussions.

\section{REFERENCES}

(1) Lewis, J. A. Colloidal processing of ceramics. I. Am. Ceram. Soc. 2000, 83 (10), 2341-2359.

(2) Requena, J.; Moreno, R.; Moya, J. S. Alumina and Alumina/ Zirconia Multilayer Composites Obtained by Slip Casting. I. Am. Ceram. Soc. 1989, 72 (8), 1511-1513.

(3) Tallon, C.; Limacher, M.; Franks, G. V. Effect of particle size on the shaping of ceramics by slip casting. I. Eur. Ceram. Soc. 2010, 30 (14), 2819-2826.

(4) Chabert, F.; Dunstan, D. E.; Franks, G. V. Cross linked polyvinyl alcohol as a binder for gelcasting and green machining. I. Am. Ceram. Soc. 2008, 91 (10), 3138.

(5) Santanach Carreras, E.; Chabert, F.; Dunstan, D. E.; Franks, G. V. Avoiding 'mud' cracks during drying of thin films from aqueous colloidal suspensions. L. Colloid Interface Sci. 2007, 313 (1), 160.

(6) Hirata, Y.; Matsushita, S.; Ishihara, Y.; Katsuki, H. Colloidal Processing and Mechanical Properties of Whisker Reinforced Mullite Matrix Composites. I. Am. Ceram. Soc. 1991, 74 (10), 2438-2442.

(7) Khvostov, V. V.; Konyashin, I. Y.; Shouleshov, E. N.; Babaev, V. G.; Guseva, M. B. Surface modification of boron nitride in hydrogen plasma. Appl. Surf. Sci. 2000, 157 (3), 178-184.

(8) Xu, Y.; Chung, D. D. L. Increasing the thermal conductivity of boron nitride and aluminum nitride particle epoxy matrix composites by particle surface treatments. Compos. Interfaces 2000, 7 (4), 243256.

(9) Zhi, C.; Bando, Y.; Tang, C.; Golberg, D. Engineering of electronic structure of boron nitride nanotubes by covalent functionalization. Phvs. Rev. B: Condens. Matter Mater. Phys. 2006, 74 (15), 153413.

(10) Ikuno, T.; Sainsbury, T.; Okawa, D.; Fréchet, J. M. J.; Zettl, A. Amine functionalized boron nitride nanotubes. Solid State Commun. 2007, 142 (11), 643-646.

(11) Sainsbury, T.; Ikuno, T.; Okawa, D.; Pacilé, D.; Fréchet, J. M. J.; Zettl, A. Self assembly of gold nanoparticles at the surface of amine and thiol functionalized boron nitride nanotubes. L.Phvs. Chem. C 2007, 111 (35), 12992-12999.

(12) Zhi, C. Y.; Bando, Y.; Terao, T.; Tang, C. C.; Kuwahara, H.; Golberg, D. Chemically activated boron nitride nanotubes. Chem.

Asian J. 2009, 4 (10), 1536-1540.

(13) Joni, I. M.; Balgis, R.; Ogi, T.; Iwaki, T.; Okuyama, K. Surface functionalization for dispersing and stabilizing hexagonal boron nitride nanoparticle by bead milling. Colloids Surf. A 2011, 388 (1-3), 49-58.

(14) Lin, Y.; Williams, T. V.; Xu, T. B.; Cao, W.; Elsayed Ali, H. E.; Connell, J. W. Aqueous Dispersions of Few Layered and Monolayered Hexagonal Boron Nitride Nanosheets from Sonication Assisted Hydrolysis: Critical Role of Water. L. Phys. Chem. C 2011, 115 (6), 2679-2685.

(15) Dai, X. J.; Chen, Y.; Chen, Z.; Lamb, P. R.; Li, L. H.; du Plessis, J.; McCulloch, D. G.; Wang, X. Controlled surface modification of boron nitride nanotubes. Nanotechnology 2011, 22 (24), 245301.

(16) Ciofani, G.; Genchi, G. G.; Liakos, I.; Athanassiou, A.; Dinucci, D.; Chiellini, F.; Mattoli, V. A simple approach to covalent functionalization of boron nitride nanotubes. $\underline{\text {. Colloid Interface Sci. }}$ 2012, 374 (1), 308-314.

(17) Zhou, S. J.; Ma, C. Y.; Meng, Y. Y.; Su, H. F.; Zhu, Z.; Deng, S. L.; Xie, S. Y. Activation of boron nitride nanotubes and their polymer composites for improving mechanical performance. Nano technology 2012, 23 (5), 055708.
(18) Kim, K.; Kim, J. Fabrication of thermally conductive composite with surface modified boron nitride by epoxy wetting method. Ceram. Int. 2014, 40 (4), 5181-5189.

(19) Kim, K.; Kim, M.; Hwang, Y.; Kim, J. Chemically modified boron nitride epoxy terminated dimethylsiloxane composite for improving the thermal conductivity. Ceram. Int. 2014, 40 (1), 2047-2056.

(20) Lee, D.; Lee, B.; Park, K. H.; Ryu, H. J.; Jeon, S.; Hong, S. H. Scalable Exfoliation Process for Highly Soluble Boron Nitride Nanoplatelets by Hydroxide Assisted Ball Milling. Nano Lett. 2015, 15 (2), 1238-1244.

(21) Sainsbury, T.; O’Neill, M. K.; Passarelli, M.; Seraffon, D.; Gohil, S.; Gnaniah, S. J.; Rae, A.; Coleman, J. N. Dibromocarbene Functionalization of Boron Nitride Nanosheets: Toward Band Gap Manipulation and Nanocomposite Applications. Chem. Mater. 2014, 26 (24), 7039-7050.

(22) Xie, S. Y.; Wang, W.; Fernando, K. A. S.; Wang, X.; Lin, Y.; Sun, Y. P. Solubilization of boron nitride nanotubes. Chem. Commun. 2005, No. 29, 3670-3672.

(23) Zhi, C.; Bando, Y.; Tang, C.; Xie, R.; Sekiguchi, T.; Golberg, D. Perfectly Dissolved Boron Nitride Nanotubes Due to Polymer Wrapping. I. Am. Chem. Soc. 2005, 127 (46), 15996-15997.

(24) Wu, X.; An, W.; Zeng, X. C. Chemical Functionalization of Boron-Nitride Nanotubes with NH3 and Amino Functional Groups. L Am Chem Soc 2006, 128 (36), 12001-12006.

(25) Zhi, C.; Bando, Y.; Tang, C.; Honda, S.; Sato, K.; Kuwahara, H.; Golberg, D. Purification of Boron Nitride Nanotubes through Polymer Wrapping. I. Phys. Chem. B 2006, 110 (4), 1525-1528.

(26) Wang, W.; Bando, Y.; Zhi, C.; Fu, W.; Wang, E.; Golberg, D. Aqueous Noncovalent Functionalization and Controlled Near Surface Carbon Doping of Multiwalled Boron Nitride Nanotubes. L. Am. Chem. Soc. 2008, 130 (26), 8144-8145.

(27) Ciofani, G.; Raffa, V.; Menciassi, A.; Cuschieri, A. Folate functionalized boron nitride nanotubes and their selective uptake by glioblastoma multiforme cells: Implications for their use as boron carriers in clinical boron neutron capture therapy. Nanoscale Res. Lett. 2009, 4 (2), 113-121.

(28) Lin, Y.; Williams, T. V.; Connell, J. W. Soluble, Exfoliated Hexagonal Boron Nitride Nanosheets. I. Phvs. Chem. Lett. 2010, 1 (1), 277-283.

(29) Terao, T.; Bando, Y.; Mitome, M.; Zhi, C.; Tang, C.; Golberg, D. Thermal Conductivity Improvement of Polymer Films by Catechin Modified Boron Nitride Nanotubes. I. Phvs. Chem. C 2009, 113 (31), 13605-13609.

(30) Yu, J.; Chen, Y.; Cheng, B. M. Dispersion of boron nitride nanotubes in aqueous solution with the help of ionic surfactants. Solid State Commun. 2009, 149 (19), 763-766.

(31) Li, T. L.; Hsu, S. L. C. Enhanced Thermal Conductivity of Polyimide Films via a Hybrid of Micro and Nano Sized Boron Nitride. I Phvs Chem B 2010, 114 (20), 6825-6829.

(32) Lin, Y.; Williams, T. V.; Cao, W.; Elsayed Ali, H. E.; Connell, J. W. Defect Functionalization of Hexagonal Boron Nitride Nanosheets. I. Phvs. Chem. C 2010, 114 (41), 17434-17439.

(33) Gao, Z.; Zhi, C.; Bando, Y.; Golberg, D.; Serizawa, T. Noncovalent Functionalization of Disentangled Boron Nitride Nanotubes with Flavin Mononucleotides for Strong and Stable Visible Light Emission in Aqueous Solution. ACS Appl. Mater. Interfaces 2011, 3 (3), 627-632.

(34) Lee, C. H.; Zhang, D.; Yap, Y. K. Functionalization, Dispersion, and Cutting of Boron Nitride Nanotubes in Water. I. Phvs. Chem. C 2012, 116 (2), 1798-1804.

(35) Wang, Y.; Shi, Z.; Yin, J. Boron nitride nanosheets: large scale exfoliation in methanesulfonic acid and their composites with polybenzimidazole. I. Mater. Chem. 2011, 21 (30), 11371-11377.

(36) Yan, H.; Tang, Y.; Su, J.; Yang, X. Enhanced thermal mechanical properties of polymer composites with hybrid boron nitride nanofillers. Appl. Phys. A: Mater. Sci. Process. 2014, 114 (2), $331-337$ 
(37) Lei, W.; Mochalin, V. N.; Liu, D.; Qin, S.; Gogotsi, Y.; Chen, Y. Boron nitride colloidal solutions, ultralight aerogels and freestanding membranes through one step exfoliation and functionalization. Nat. Commun. 2015, 6, 8849.

(38) Larson, R. G. The Structure and Rheology of Complex Fluids; 1999.

(39) Boinovich, L. B.; Emelyanenko, A. M.; Pashinin, A. S.; Lee, C. H.; Drelich, J.; Yap, Y. K. Origins of Thermodynamically Stable Superhydrophobicity of Boron Nitride Nanotubes Coatings. Langmuir 2012, 28 (2), 1206-1216.

(40) Li, X.; Qiu, H.; Liu, X.; Yin, J.; Guo, W. Wettability of Supported Monolayer Hexagonal Boron Nitride in Air. Adv. Funct. Mater. 2017, 27 (19), 1603181.

(41) Achour, H.; Achour, A.; Solaymani, S.; Islam, M.; Vizireanu, S.; Arman, A.; Ahmadpourian, A.; Dinescu, G. Plasma surface functionalization of boron nitride nano sheets. Diamond Relat. Mater. 2017, 77, 110-115.

(42) Ji, H.; Ju, H.; Lan, R.; Wu, P.; Sun, J.; Chao, Y.; Xun, S.; Zhu, W.; Li, H. Phosphomolybdic acid immobilized on ionic liquid modified hexagonal boron nitride for oxidative desulfurization of fuel. RSC Adv. 2017, 7 (85), 54266-54276.

(43) Wang, B. B.; Zhu, M. K.; Ostrikov, K.; Levchenko, I.; Keidar, M.; Shao, R. W.; Zheng, K.; Gao, D. Conversion of vertically aligned boron nitride nanowalls to photoluminescent $\mathrm{CN}$ compound nanorods: Efficient composition and morphology control via plasma technique. Carbon 2016, 109, 352-362.

(44) Johnson, S. B.; Franks, G. V.; Scales, P. J.; Boger, D. V.; Healy, T. W. Surface chemistry rheology relationships in concentrated mineral suspensions. Int. I. Miner. Process. 2000, 58 (1-4), 267-304. (45) Mewis, J.; Wagner, J. N. Colloidal Suspension Rheology; Cambridge Series in Chemical Engineering; Cambridge, U.K., 2013. 